\title{
Efficacy of early treatment with hydroxychloroquine in people with mild to moderate COVID-19: a systematic review and meta-analysis
}

Adrian V. Hernandez ${ }^{1,2}$, John Ingemi III', Michael Sherman ${ }^{1}$, Vinay Pasupuleti ${ }^{3}$, Joshuan J. Barboza ${ }^{2}$, Alejandro Piscoya ${ }^{2}$, Yuani M. Romann ${ }^{1}$, C. Michael White ${ }^{1}$

\author{
${ }^{1}$ Department of Pharmacy Practice, University of Connecticut School of Pharmacy, \\ Storrs, CT, USA \\ 2Unidad de Revisiones Sistemáticas y Meta-análisis (URSIGET), Vicerrectorado de \\ Investigación, Universidad San Ignacio de Loyola (USIL), Lima, Peru \\ ${ }^{3}$ Department of Research, Cello Health, Yardley, PA, USA
}

Submitted: 2 July 2021; Accepted: 17 October 2021

Online publication: 24 October 2021

Arch Med Sci 2022; 18 (4): 939-948

DOI: https://doi.org/10.5114/aoms/143147

Copyright $\odot 2022$ Termedia \& Banach

\begin{abstract}
A bstract
Introduction: No early treatment intervention for COVID-19 has proven effective to date. We systematically reviewed the efficacy of hydroxychloroquine as early treatment for COVID-19.

Material and methods: Randomized controlled trials (RCTs) evaluating hydroxychloroquine for early treatment of COVID-19 were searched in five engines and preprint websites until September 14, 2021. Primary outcomes were hospitalization and all-cause mortality. Secondary outcomes included COVID-19 symptom resolution, viral clearance, and adverse events. Inverse variance random-effects meta-analyses were performed and quality of evidence (QoE) per outcome was assessed with GRADE methods.

Results: Five RCTs $(n=1848)$ were included. The comparator was placebo in four RCTs and usual care in one RCT. The RCTs used hydroxychloroquine total doses between 1,600 and 4,400 mg and had follow-up times between 14 and 90 days. Compared to the controls, early treatment with hydroxychloroquine did not reduce hospitalizations $(R R=0.80,95 \% \mathrm{Cl}: 0.47-1.36$, $I^{2}=2 \%, 5$ RCTs, low QoE), all-cause mortality ( $R R=0.77,95 \% \mathrm{Cl}: 0.16-3.68$, $I^{2}=0 \%, 5$ RCTs, very low $\mathrm{QoE}$ ), symptom resolution ( $\mathrm{RR}=0.94,95 \% \mathrm{Cl}$ : $0.77-1.16, I^{2}=71 \%, 3$ RCTs, low $\left.\mathrm{QoE}\right)$ or viral clearance at 14 days $(\mathrm{RR}=1.02$, $95 \% \mathrm{Cl}: 0.82-1.27, I^{2}=65 \%, 2 \mathrm{RCTs}$, low QoE). There was a larger non-significant increase of adverse events with hydroxychloroquine vs. controls $(R R=2.17$, $95 \% \mathrm{Cl}: 0.86-5.45, l^{2}=92 \%, 5 \mathrm{RCTs}$, very low QoE).

Conclusions: Hydroxychloroquine was not efficacious as early treatment for COVID-19 infections in RCTs with low to very low quality of evidence for all outcomes. More RCTs are needed to elucidate the efficacy of hydroxychloroquine as early treatment intervention.
\end{abstract}

Key words: hydroxychloroquine, COVID-19, efficacy, safety, early treatment.

\section{Introduction}

Over 43 million people in the United States (US) have contracted COVID-19, resulting in $\sim 698,000$ deaths [1]. The surges in cases have brought with them over 3,000,000 hospitalizations that threaten to overwhelm the strained healthcare system [1]. One approach to reducing the impact of COVID-19 on the healthcare system is through early treatment of patients in the outpatient setting.

\author{
Corresponding author: \\ Adrian V. Hernandez MD, PhD \\ University of Connecticut \\ School of Pharmacy, \\ 69 N Eagleville Rd U-3092 \\ Storrs, CT 06269, USA \\ E-mail: \\ adrian.hernandez-diaz@ \\ uconn.edu
}


The monoclonal antibody products bamlanivimab [2] and casirivimab/imdevimab [3] recently received emergency use authorization from the Food and Drug Administration (FDA) for the treatment of COVID-19 patients at high risk for progressing to hospitalization. While these early treatment trials were positive, bamlanivimab was found inefficacious for the treatment of hospitalized COVID-19 patients [4], supporting the hypothesis that antiviral therapy is most effective early in the course of disease [5].

The results of hydroxychloroquine randomized controlled trials (RCTs) and cohort studies for the treatment of hospitalized patients have been lackluster $[6,7]$ and its emergency use authorization was revoked by the FDA [8]. However, at the November 2020 American Medical Association meeting, delegates tried to get the organization to revoke its statement discouraging the use of hydroxychloroquine for COVID-19, especially for the early outpatient treatment of the disease [9]. That same month, several panelists at a US Senate hearing touted hydroxychloroquine's outpatient use in COVID-19, and asked for its emergency use authorization to be reinstated [10]. If hydroxychloroquine is effective and safe in the early treatment of COVID-19, it would be markedly less expensive than monoclonal antibody therapy and much more readily available to roll out to the general public. However, the use of hydroxychloroquine may have adverse events and shunting utilization to COVID-19 patients could cause shortages for those patients who need hydroxychloroquine for autoimmune diseases and malaria [11].

In this systematic review with meta-analyses, we assessed the efficacy and safety of hydroxychloroquine in early onset treatment of COVID-19 from all the available randomized controlled trials.

\section{Material and methods}

\section{Data sources and searches}

Three investigators (C.M.W., V.P., and A.V.H.) developed the search strategy, which was revised and approved by the other investigators. We searched the following databases from December 1, 2019 to September 14, 2021: PubMed-MEDLINE, EMBASE-OVID, Scopus, Web of Science, the Cochrane Library, bioRxiv (www.biorxiv.org), Preprints (www.preprints.org), Clinical Trials.gov, the World Health Organization International Clinical Trials Registry Platform (www.who.int/ictrp/en/), and the Chinese Clinical Trials Registry (www.chictr.org.cn). The PubMed search strategy is shown in the Supplementary file.

\section{Study selection}

We included randomized controlled studies (RCTs) in any language reporting benefit or harm outcomes from use of hydroxychloroquine as early treatment (i.e. a few days from symptom onset to enrolment) in outpatients with mild to moderate reverse transcription-polymerase chain reaction (RT-PCR)-confirmed COVID-19. We excluded studies in hospitalized COVID-19 patients, even though patients had mild to moderate disease and/or early disease, studies of prophylaxis with hydroxychloroquine (i.e. in those without COVID-19), and cohort studies evaluating hydroxychloroquine as early treatment of COVID-19. Three investigators (A.V.H., V.P., Y.M.R.) independently screened each record title and abstract for potential inclusion. Three investigators (V.P., J.J.B., Y.M.R.) then read the full text of the records whose abstracts had been selected by at least one investigator. Discrepancies were resolved through discussion or by a fourth investigator (A.V.H.).

\section{Outcomes}

Primary outcomes were hospitalization and allcause mortality. Secondary outcomes were intensive care unit (ICU) admission, need of mechanical ventilation, COVID-19 symptom resolution, viral clearance in nasopharyngeal swabs, adverse events, and specific adverse events (e.g. diarrhea, headache, QTc prolongation).

\section{Data extraction}

Two investigators (A.P., J.J.B.) independently extracted the following variables from studies: study setting, country, mean age, proportion of males, time from symptom onset in days, proportion of chronic coexisting diseases, hydroxychloroquine dose and duration, type of control and description, additional drug interventions, primary and secondary outcomes, and time of follow-up. Discrepancies were resolved through discussion or by a third investigator (A.V.H.).

\section{Risk of bias assessment}

Two investigators (A.P., J.J.B.) independently assessed risk of bias (RoB) of randomized controlled trials with the Cochrane Risk of Bias 2.0 tool for RCTs [12, 13]; disagreements were resolved by discussion with a third investigator (A.V.H.). RoB 2 assesses five domains: bias due to the randomization process, deviations from intended interventions, missing outcome data, measurement of the outcome, and selection of the reported result. RoB of each domain and each RCT was described as low, some concerns or high.

\section{Statistical analysis}

We reported our systematic review according to 2009 PRISMA guidelines [14]. Inverse variance 
random effect meta-analyses were performed to evaluate effect of hydroxychloroquine vs. control on outcomes when outcome data were available for at least two RCTs or cohorts judged to have homogeneous study characteristics. Effects of meta-analyses were reported as relative risks (RR) for dichotomous outcomes and as mean differences (MD) for continuous outcomes, along with their 95\% confidence intervals (Cls). Cls of effects were adjusted with the Hartung-Knapp method [15], and the between study variance $\tau^{2}$ was calculated with the Paule-Mandel method. Heterogeneity of effects among studies was quantified with the ${ }^{2}$ statistic $\left({ }^{2}>60 \%\right.$ means high heterogeneity). The meta package of R 3.5.1 (www.r-project.org) was used for meta-analyses. The quality of evidence (QoE) was evaluated using the GRADE methodology, which covers five aspects: risk of bias, inconsistency, indirectness, imprecision, and publication bias [16]. Quality of evidence was evaluated per outcome and described in summary of findings (SoF) tables; GRADEpro GDT was used to create SoF tables [17].

\section{Results}

\section{Selection of studies}

Our comprehensive search yielded 9551 citations with an additional 927 citations identified through other sources, including backwards citation tracking. After removing duplicates and applying our inclusion and exclusion criteria (Supplementary Figure S1), we identified five RCTs [18-22] $(n=1848)$ which were all homogeneous enough to warrant meta-analyses.

\section{Characteristics of included studies}

The general characteristics of the included RCTs are included in Table I. Placebo was the comparator in four RCTs [19-22] while usual care was the comparator in the open label one [18]. The five RCTs used hydroxychloroquine total doses between 1,600 and 4,400 mg and had follow-up times between 14 and 90 days. Mean or median ages ranged between 37 and 53 years, males between $31 \%$ and $55 \%$, median time of COVID-19 symptom onset between 3 and 7 days, with most individuals having symptom onset within 9 days, and the proportion of individuals without coexisting disease between $36 \%$ and $68 \%$.

\section{Risk of bias of included studies}

One RCT had high risk of bias due to missing outcome data [19], two RCTs had some concerns of bias due to deviations from intended interventions and selection in the reported result [18] and due to bias in the randomization process [21], and two RCTs had low risk of bias [20, 22] (Supplementary Figure S2).

\section{Effects of early treatment with hydroxichloroquine on outcomes}

In comparison to the control group, hydroxychloroquine non-significantly reduced hospitalizations by $20 \%(\mathrm{RR}=0.80,95 \% \mathrm{Cl}: 0.47-1.36$, $R^{2}=2 \%, 5$ RCTs, low QoE, Figure 1) and all-cause mortality by $23 \%(\mathrm{RR}=0.77,95 \% \mathrm{Cl}: 0.16-3.68$, $P^{2}=0 \%, 5$ RCTs, very low QoE, Figure 2). Also, hydroxychloroquine had no effect on COVID-19 symptom resolution $(\mathrm{RR}=0.94,95 \% \mathrm{Cl}$ : 0.77-1.16, $R^{2}=71 \%$, 3 RCTs, low QoE, Supplementary Figure S3), time to COVID-19 symptom resolution (MD = -0.16 days, $95 \% \mathrm{Cl}$ : -4.56 to 4.25 days, $I^{2}=80 \%$, 2 RCTs, very low QoE, Supplementary Figure S4) or on viral clearance at 14 days $(R R=1.02,95 \% \mathrm{Cl}$ : $0.82-1.27, I^{2}=65 \%, 2$ RCTs, low QoE, Supplementary Figure S5) in comparison to the control group.

There were no data about ICU admissions or need of mechanical ventilation in RCTs. Hydroxychloroquine non-significantly increased risks of adverse events in comparison to the control group $\left(\mathrm{RR}=2.17,95 \% \mathrm{Cl}: 0.86-5.45, \rho^{2}=92 \%, 5\right.$ RCTs, very low QoE, Figure 3). Reports of specific adverse events in the RCTs were very scarce.

\section{Quality of evidence of effects}

The quality of evidence was low to very low for all outcomes (Table II). The main drivers of poor quality of evidence in RCTs were high risk of bias, imprecision of effects and inconsistency.

\section{Discussion}

In our systematic review we found that hydroxychloroquine as early treatment for COVID-19 was not associated with lower hospitalization, allcause mortality, or overall adverse events risks vs. controls (usual care or placebo) in five RCTs. There was no effect of hydroxychloroquine on COVID-19 symptom resolution or viral clearance at 14 days. No data on other outcomes such as ICU admissions, need for mechanical ventilation, or specific adverse events were reported. The quality of evidence was low to very low in all outcomes.

The $20 \%$ relative reductions in hospitalizations in RCTs is encouraging, especially since three of the biggest RCTs had the same direction of effect in favor of hydroxychloroquine, but none of the individual risks was significant across RCTs. If this were a real benefit of therapy, reducing relative risks of hospitalizations in those recently contracting COVID-19 by one fifth would make a difference in the overstressed healthcare system. However, more RCTs of higher methodologic quality are needed for us to adequately assess 


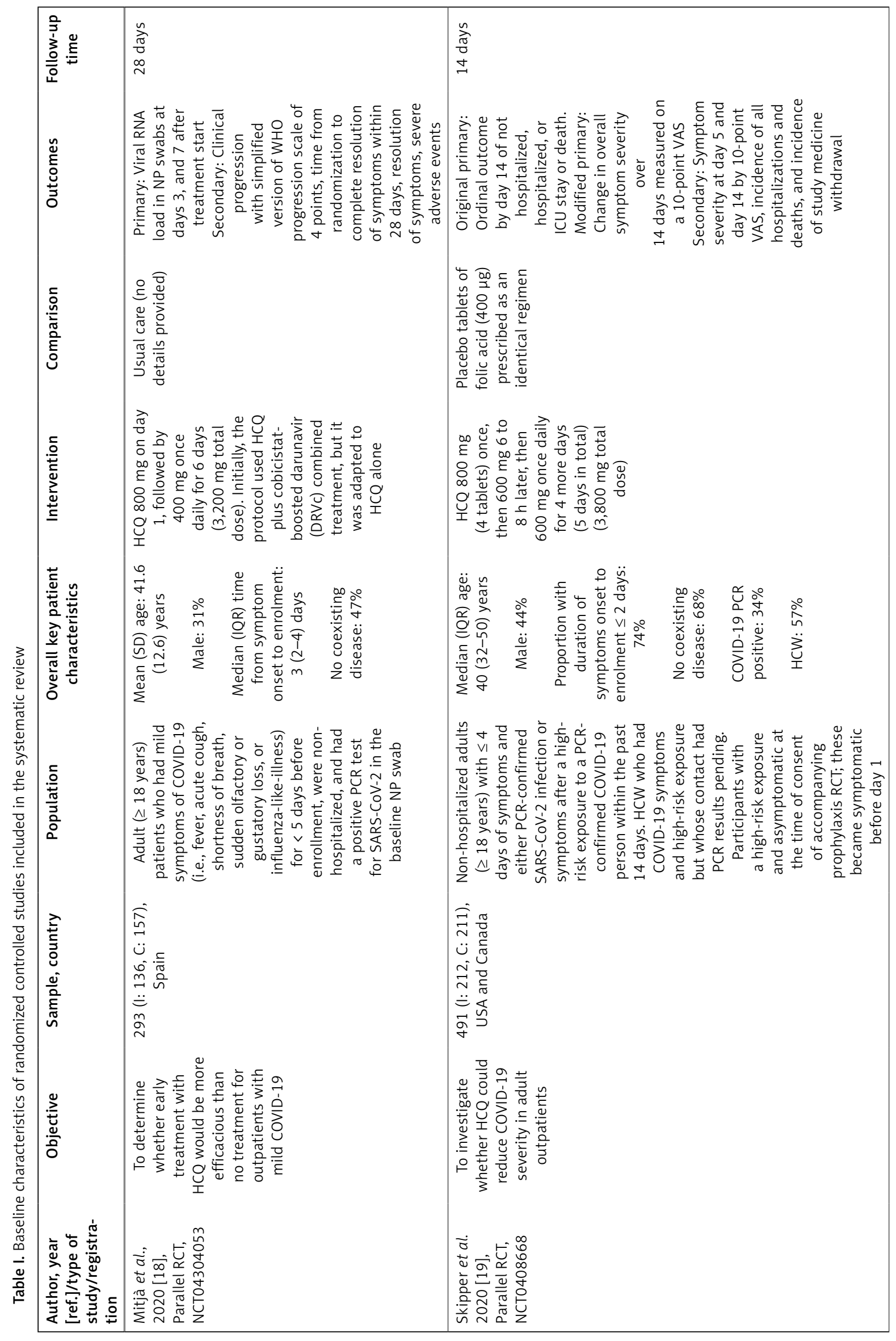




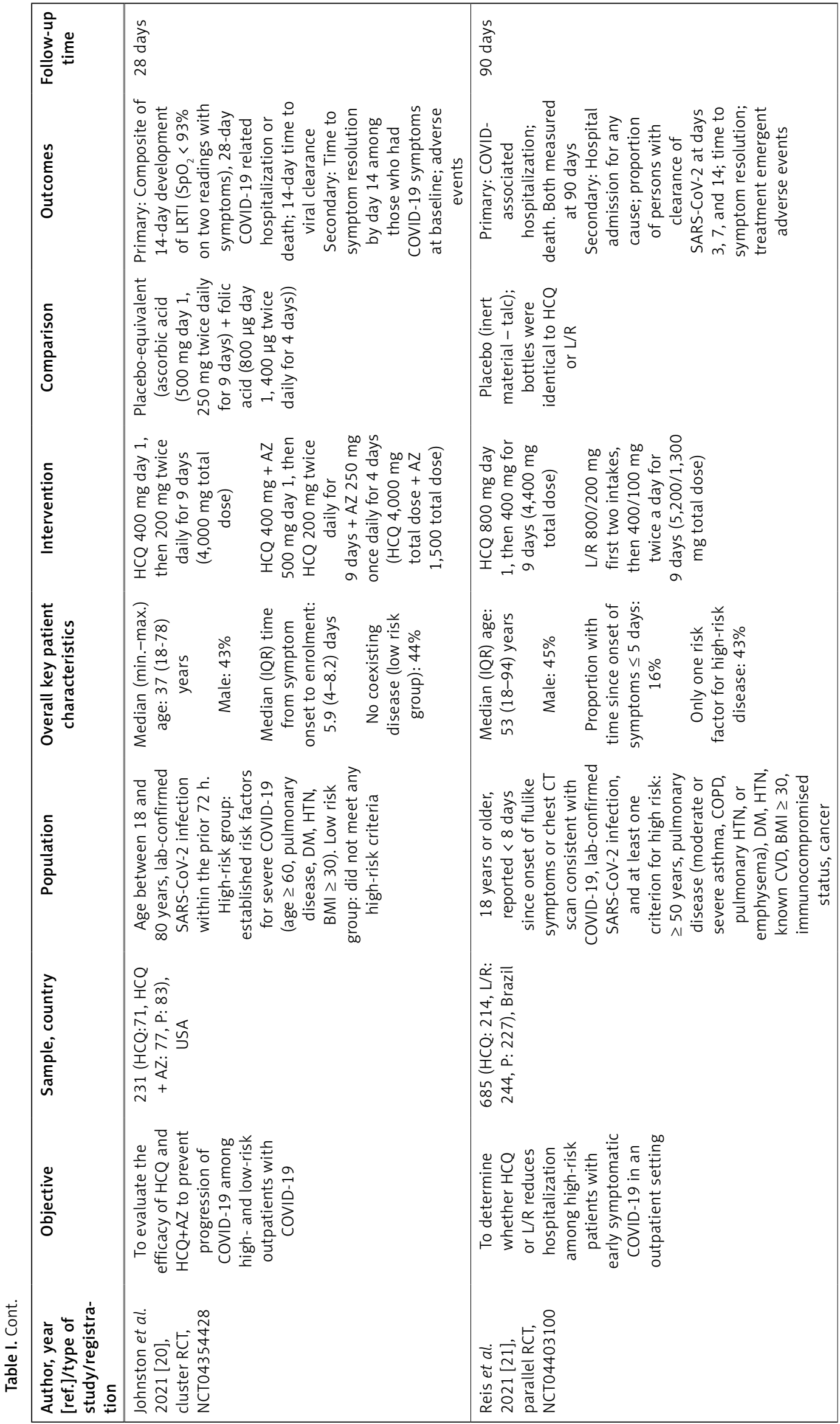




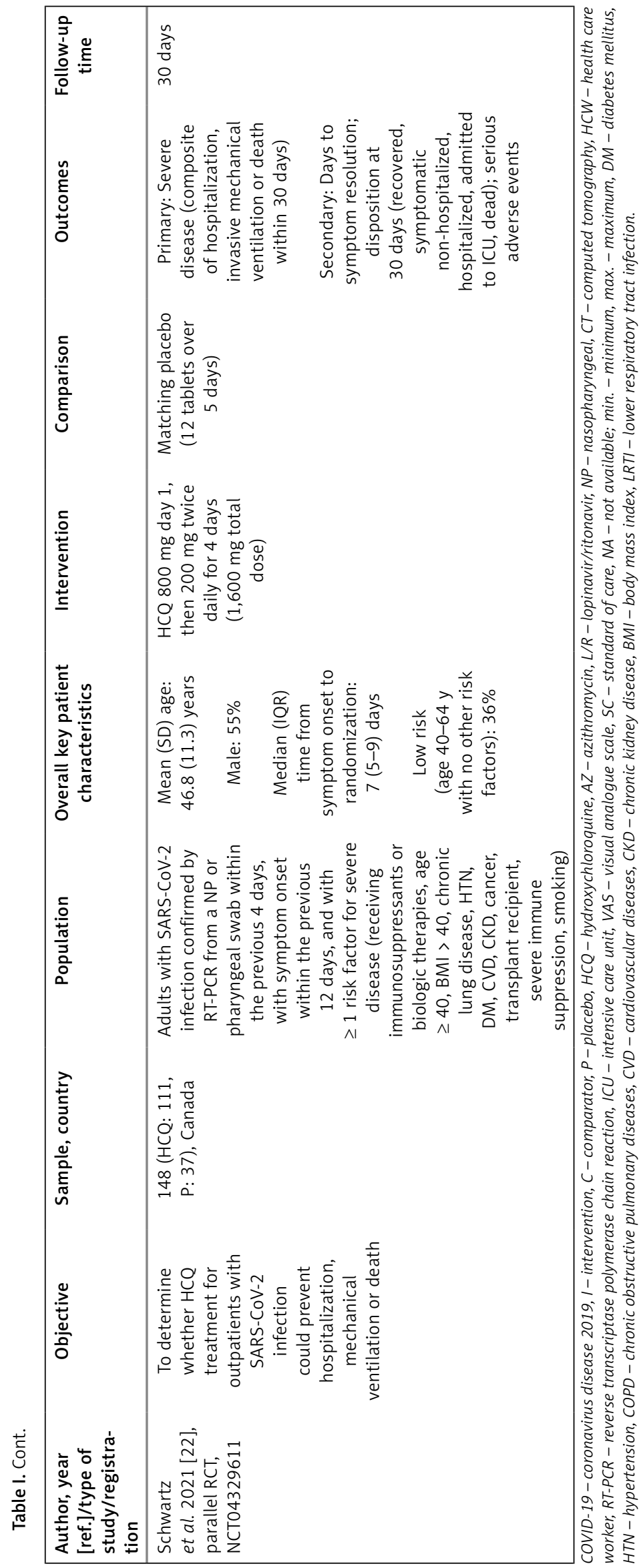




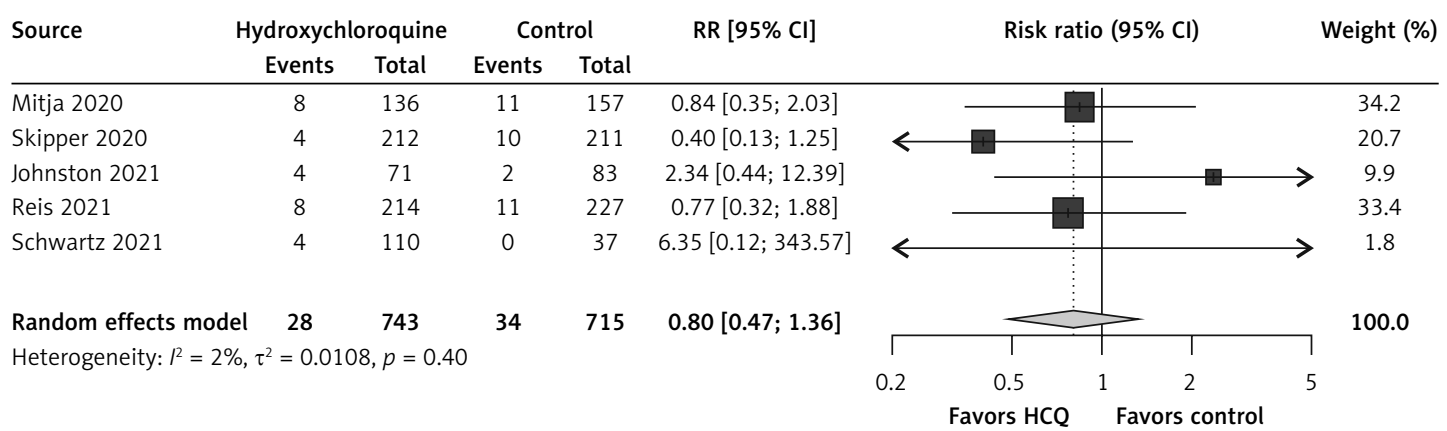

Figure 1. Effect of early treatment with hydroxychloroquine on hospitalization

\begin{tabular}{|c|c|c|c|c|c|c|c|c|c|c|c|}
\hline \multirow[t]{2}{*}{ Source } & \multicolumn{2}{|c|}{ Hydroxychloroquine } & \multicolumn{2}{|c|}{ Control } & \multirow[t]{2}{*}{$\operatorname{RR}[95 \% \mathrm{Cl}]$} & & \multirow{2}{*}{\multicolumn{2}{|c|}{ Risk ratio $(95 \% \mathrm{Cl})$}} & & \multirow{2}{*}{\multicolumn{2}{|c|}{ Weight (\%) }} \\
\hline & Events & Total & Events & Total & & & & & & & \\
\hline Mitja 2020 & 0 & 136 & 0 & 157 & $1.00[0.02 ; 50.57]$ & $\leftarrow$ & & & & $\rightarrow$ & 16.0 \\
\hline Skipper 2020 & 1 & 201 & 1 & 194 & $0.97[0.06 ; 15.32]$ & $\leftarrow$ & & & & $\rightarrow$ & 32.2 \\
\hline Johnston 2021 & 0 & 71 & 0 & 83 & $1.00[0.02 ; 50.36]$ & $\leftarrow$ & & & & $\rightarrow$ & 16.0 \\
\hline Reis 2021 & 0 & 214 & 1 & 227 & $0.34[0.01 ; 8.57]$ & $\leftarrow$ & & & & & 23.6 \\
\hline Schwartz 2021 & 0 & 110 & 0 & 37 & $1.00[0.01 ; 91.02]$ & $<$ & & & & $\rightarrow$ & 12.1 \\
\hline Random effects model & 1 & 733 & 2 & 698 & $0.77[0.16 ; 3.68]$ & & & & & & 100.0 \\
\hline \multirow{2}{*}{\multicolumn{6}{|c|}{ Heterogeneity: $P^{2}=0 \%, \tau^{2}=0, p=0.99$}} & 1 & 1 & T & 1 & 7 & \\
\hline & & & & & & $0.1 \quad 0.2$ & 0.5 & 1 & 5 & 10 & \\
\hline
\end{tabular}

Figure 2. Effect of early treatment with hydroxychloroquine on all-cause mortality

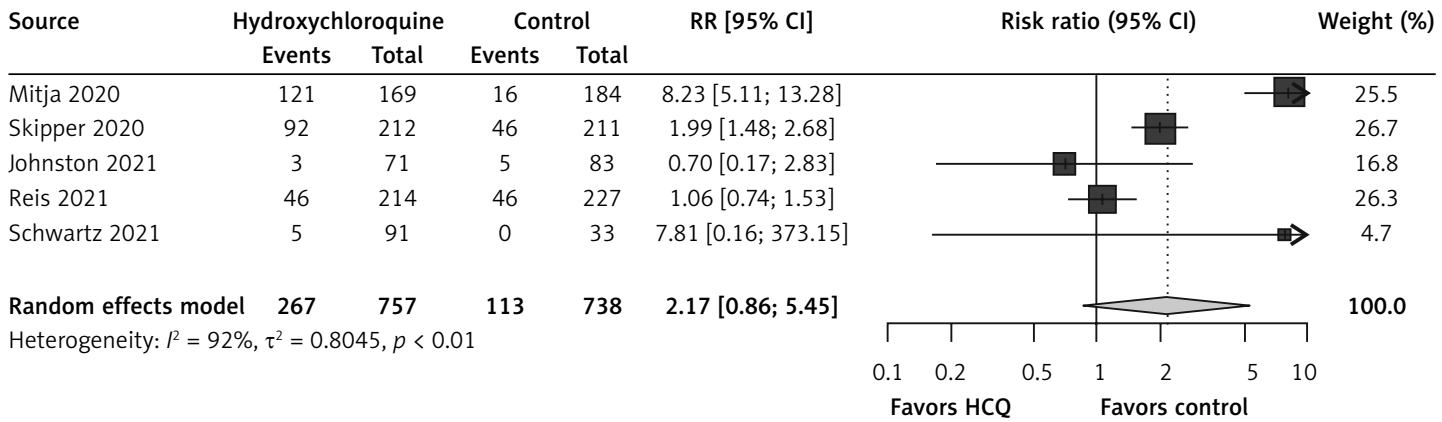

Figure 3. Effect of early treatment with hydroxychloroquine on adverse events

this outcome with the use of early treatment with hydroxychloroquine in the future.

The RCTs found no impact on all-cause mortality; probable reasons included scarcity of events (i.e. one event per arm in Skipper et al. [19] and one event in the control arm in Reis et al. [21]), and also short time of follow-up as Skipper et al. [19] only had 14 days, Mitjà et al. [18] and Johnston et al. [20] only had 28 days, and Schwartz et al. [22] only had 30 days, so it could have been too soon to see mortality reductions. The dose of hydroxychloroquine therapy was not a viable explanation for the lack of effect on all-cause mortality across RCTs as the total doses in the RCTs ranged from $3,200 \mathrm{mg}$ to $4,400 \mathrm{mg}$, with the exception of the small RCT by Schwartz et al. [22] with a total dose of 1,600 mg. The duration of hydroxychloroquine was not a viable explanation either, with RCTs providing hydroxychloroquine therapy for 5 to 9 days. Three recent systematic reviews and meta-analyses including RCTs until October 16, 2020 did not evaluate mortality effects of hydroxychloroquine in outpatients [23-25]; two other recent systematic reviews and meta-analyses including RCTs until October 15, $2020[26,27]$ only assessed mortality effects in COVID-19 outpatients using the Mitja et al. [18] and Skipper et al. [19] RCTs.

Hydroxychloroquine for the early treatment of COVID-19 would compete against the monoclonal antibody products bamlanivimab [2] and casirivimab/imdevimab [3] that recently received emergency use authorization from the FDA for the treatment of COVID-19 patients at high risk for progressing to hospitalization. These drugs will cost between $\$ 1,250$ and $\$ 1,500$ per dose according to governmental contracts. Bamlanivimab was authorized based on the results from the 'Blocking Viral Attachment and Cell Entry with SARSCoV-2 Neutralizing Antibodies' (BLAZE-1) RCT [28]. In the combined bamlanivimab dosing group, the incidence of hospitalizations or emergency department visits was non-significantly lower 
Table II. Summary of findings table for the effects of early treatment with hydroxychloroquine vs. control in COVID-19 patients

\begin{tabular}{|c|c|c|c|c|c|}
\hline \multirow[t]{2}{*}{ Outcomes } & \multicolumn{2}{|c|}{ Anticipated absolute effects* $(95 \% \mathrm{Cl})$} & \multirow{2}{*}{$\begin{array}{l}\text { Relative effect } \\
\qquad(95 \% \mathrm{Cl})\end{array}$} & \multirow{2}{*}{$\begin{array}{l}\text { No. of partici- } \\
\text { pants } \\
\text { (studies) }\end{array}$} & \multirow{2}{*}{$\begin{array}{l}\text { Certainty of the } \\
\text { evidence } \\
\text { (GRADE) }\end{array}$} \\
\hline & Risk with control & $\begin{array}{c}\text { Risk with } \\
\text { hydroxychloroquine }\end{array}$ & & & \\
\hline $\begin{array}{l}\text { Hospitalization } \\
\text { follow-up: } \\
\text { range } 14 \text { days } \\
\text { to } 90 \text { days }\end{array}$ & 5 per 100 & $\begin{array}{c}4 \text { per } 100 \\
(2 \text { to } 6)\end{array}$ & $\begin{array}{c}R R=0.80 \\
(0.47 \text { to } 1.36)\end{array}$ & $\begin{array}{c}1458 \\
\text { (5 RCTs) }\end{array}$ & $\underset{\text { Low }^{a}}{\bigoplus \bigoplus \bigcirc}$ \\
\hline $\begin{array}{l}\text { All-cause } \\
\text { mortality } \\
\text { follow-up: } \\
\text { range } 14 \text { days } \\
\text { to } 90 \text { days }\end{array}$ & 0 per 100 & $\begin{array}{l}0 \text { per } 100 \\
(0 \text { to } 1)\end{array}$ & $\begin{array}{c}R R=0.77 \\
(0.16 \text { to } 3.68)\end{array}$ & $\begin{array}{c}1431 \\
(5 \mathrm{RCTs})\end{array}$ & $\begin{array}{l}\oplus \bigcirc \bigcirc \bigcirc \\
\text { Very low } w^{\mathrm{a}, \mathrm{b}}\end{array}$ \\
\hline $\begin{array}{l}\text { COVID-19 } \\
\text { symptom } \\
\text { resolution } \\
\text { follow-up: } \\
\text { range } 14 \text { days } \\
\text { to } 30 \text { days }\end{array}$ & 67 per 100 & $\begin{array}{l}63 \text { per } 100 \\
(51 \text { to } 77)\end{array}$ & $\begin{array}{c}\mathrm{RR}=0.94 \\
(0.77 \text { to } 1.16)\end{array}$ & $\begin{array}{c}675 \\
\text { (3 RCTs) }\end{array}$ & $\underset{\text { Low }^{c, d}}{\bigoplus \bigoplus \bigcirc}$ \\
\hline $\begin{array}{l}\text { Time to } \\
\text { COVID-19 } \\
\text { symptom } \\
\text { resolution } \\
\text { assessed with: } \\
\text { days follow-up: } \\
\text { range } 28 \text { days } \\
\text { to } 30 \text { days }\end{array}$ & $\begin{array}{l}\text { The mean time to } \\
\text { COVID-19 symptom } \\
\text { resolution was } \\
12.7 \text { days }\end{array}$ & $\begin{array}{c}\text { MD } 0.16 \text { days lower } \\
\text { (4.56 lower to } \\
4.25 \text { higher) }\end{array}$ & - & $\begin{array}{c}417 \\
(2 \mathrm{RCTs})\end{array}$ & $\begin{array}{l}\oplus \bigcirc \bigcirc \bigcirc \\
\text { Very lowe, }\end{array}$ \\
\hline $\begin{array}{l}\text { Viral clearance } \\
\text { assessed with: } \\
\text { RT-PCR from } \\
\text { nasopharyn- } \\
\text { geal swab fol- } \\
\text { low-up: mean } \\
14 \text { days }\end{array}$ & 62 per 100 & $\begin{array}{l}63 \text { per } 100 \\
(50 \text { to } 78)\end{array}$ & $\begin{array}{c}R R=1.02 \\
(0.82 \text { to } 1.27)\end{array}$ & $\begin{array}{c}481 \\
\text { (2 RCTs) }\end{array}$ & $\underset{\text { Low }^{h, i}}{\oplus \bigoplus \bigcirc}$ \\
\hline $\begin{array}{l}\text { Adverse events } \\
\text { follow-up: } \\
\text { range } 14 \text { days } \\
\text { to } 28 \text { days }\end{array}$ & 15 per 100 & $\begin{array}{l}33 \text { per } 100 \\
(13 \text { to } 83)\end{array}$ & $\begin{array}{c}R R=2.17 \\
(0.86 \text { to } 5.45)\end{array}$ & $\begin{array}{c}1495 \\
(5 \mathrm{RCTs})\end{array}$ & $\begin{array}{l}\oplus \bigcirc \bigcirc \bigcirc \\
\text { very low }{ }^{\mathrm{a}, \mathrm{j}, \mathrm{k}}\end{array}$ \\
\hline $\begin{array}{l}{ }^{a} \text { Very serious risk of } \\
\text { to deviations from } \\
{ }^{\circ} \text { Serious imprecisio } \\
\text { data. }{ }^{d} \text { Serious hete } \\
\text { deviations from int } \\
\text { 'Serious imprecisio } \\
\text { process in Reis } 20\end{array}$ & $\begin{array}{l}\text { due to high risk of bias } \\
\text { 2ded interventions and } \\
95 \% \mathrm{Cl} \text { of RR was } 0.16 \text { to } \\
\text { neity of effects across th } \\
\text { d interventions and sele } \\
95 \% \mathrm{Cl} \text { of } \mathrm{MD} \text { was }-4.5 \\
\text { erious heterogeneity of }\end{array}$ & $\begin{array}{l}\text { kipper } 2020 \text { due to miss } \\
\text { ction of the reported res } \\
68 \text {. 'Serious risk of bias } \\
\text { s as } l^{2}=71 \% \text {. }{ }^{\text {SSerious }} \\
\text { on of the reported result } \\
\text { to } 4.25 \text { days. " } \text { "Serious }\end{array}$ & $\begin{array}{l}\text { outcome data, a } \\
\text { and in Reis } 202 \\
\text { to high risk of bi } \\
\text { of bias due to } 5 \\
\text { ery serious heter } \\
\text { of bias due to so }\end{array}$ & $\begin{array}{l}\text { some concerns o } \\
\text { le to bias in the } \\
n \text { Skipper } 2020 \\
\text { concerns of bic } \\
\text { neity of effects } \\
\text { concerns of bic }\end{array}$ & $\begin{array}{l}\text { ias in Mitja } 2020 \text { due } \\
\text { ndomization process } \\
\text { e to missing outcome } \\
\text { in Mitja } 2020 \text { due to } \\
\text { oss trials as } I^{2}=80 \% \\
\text { of the randomizatior } \\
\text { ffects across trials a }\end{array}$ \\
\hline
\end{tabular}

(3 of $309(1.6 \%)$ vs. 9 of $143(6.3 \%)$ ) by day 29. In a 799-patient trial that is still unpublished [29], treatment with casirivimab/imdevimab was associated with a $57 \%$ reduction in COVID-19-related medical visits until day 29 , which was significantly greater than the placebo group $(p=0.024)$.

The National Institutes of Health COVID-19 Treatment Guideline Panel [2] has cautioned that there is insufficient evidence of bamlanivimab's efficacy in early outpatient treatment and has not commented on the use of casirivimab/imdevimab because the data are unpublished. As such, we cannot determine whether any of these therapies is truly beneficial in the early treatment of COVID-19 or whether one option is superior to the others. If hydroxychloroquine is subsequently found to significantly reduce hospitalizations, it would offer several advantages over monoclonal antibody therapy including a better established safety profile, lower acquisition cost, more convenient dosing form, and more ample supply for COVID-19 patients.

However, if hydroxychloroquine is not truly efficacious or effective, the adverse events associated with therapy would not be balanced out with benefits, and shunting the drug supply away from patients with autoimmune diseases could negatively impact other patients in the healthcare system. 
In a study of 3,872 patients taking hydroxychloroquine or chloroquine for autoimmune diseases [11], 27\%, 21\%, 7\%, and $2 \%$ of patients in Africa, South-East Asia, North and South America and Europe, respectively, reported running out of medication due to drug shortages in the COVID-19 era. These patients experienced poorer physical $(5.6<6.4, t(254)=5.97, p<0.001)$ and mental $(5.8<6.3, \mathrm{t}(252)=3.82, p<0.001)$ health and higher levels of rheumatic disease activity $(5.1>4.3, t(244)=4.44, p<0.001)$ as a result.

Our study has several limitations. First, all outcomes had low to very low quality of evidence mainly explained by heterogeneity of effects across trials, high risk of bias or some concerns of bias of three RCTs, and imprecision of effects. Second, there were very scarce all-mortality data across RCTs, and only two or three RCTs had information on symptom resolution or viral clearance. Third, there were no data on ICU admissions, need of mechanical ventilation, or specific adverse events. Fourth, four of the five RCTs [19-22] had fewer patients randomized than originally planned; this may have resulted in lack of power to detect effects of hydroxychloroquine on outcomes. Finally, we did not evaluate the effect of adding azithromycin to hydroxychloroquine in our study.

In conclusion, hydroxychloroquine as early treatment did not reduce hospitalizations, allcause mortality, COVID-19 symptom resolution, or viral clearance in COVID-19 outpatients from five RCTs in comparison to placebo or usual care. There also was a non-significant increase in adverse events with hydroxychloroquine as early treatment. There were no data for outcomes such as ICU admission, need of mechanical ventilation or specific adverse events. The quality of evidence was low to very low for all outcomes.

Given its low acquisition cost, relative safety, convenient administration route, and available supply, hydroxychloroquine should continue to be investigated for outpatients who test positive for COVID-19. However, hydroxychloroquine should not be recommended for acute treatment at this time because the balance of benefits to harms cannot be determined given the current literature base.

\section{Conflict of interest}

The authors declare no conflict of interest.

\section{References}

1. Centers for Disease Control and Prevention. COVID Data Tracker. Available at: https://covid.cdc.gov/covid-data-tracker/\#datatracker-home Accessed on October 02, 2021.

2. National Institutes of Health. The COVID-19 Treatment Guidelines Panel's Statement on the Emergency
Use Authorization of Bamlanivimab for the Treatment of COVID-19. 11/18/2020. Available at: https://www. covid19treatmentguidelines.nih.gov/statement-onbamlanivimab-eua/ Accessed on September 26, 2021.

3. Food and Drug Administration. Coronavirus (COVID-19) Update: FDA Authorizes Monoclonal Antibodies for Treatment of COVID-19. Available at: https://www.fda.gov/newsevents/press-announcements/coronavirus-covid-19-update-fda-authorizes-monoclonal-antibodies-treatment-covid-19 Accessed on September 26, 2021.

4. National Institutes of Health. Statement-NIH-Sponsored ACTIV-3 Trial Closes LY-CoV555 Sub-Study. 10/26/2020. Available at; https://www.niaid.nih.gov/ news-events/statement-nih-sponsored-activ-3-trial-closes-ly-cov555-sub-study. Accessed September 26, 2021.

5. Siddiqi HK, Mehra MR. COVID-19 illness in native and immunosuppressed states: a clinical-therapeutic staging proposal. J Heart Lung Transplant 2020; 39: 405-7.

6. Hernandez AV, Roman YM, Pasupuleti V, Barboza JJ, White CM. Hydroxychloroquine or chloroquine for treatment or prophylaxis of COVID-19: a living systematic review. Ann Intern Med 2020; 173: 287-96.

7. Hernandez AV, Roman YM, Pasupuleti V, Barboza JJ, White CM. Update Alert 3: hydroxychloroquine or chloroquine for the treatment or prophylaxis of COVID-19. Ann Intern Med 2020; 173: W156-7.

8. Food and Drug Administration. Coronavirus (COVID-19) Update: FDA Revokes Emergency Use Authorization for Chloroquine and Hydroxychloroquine. 6/15/2020. Available at: https://www.fda.gov/news-events/press-announcements/coronavirus-covid-19-update-fda-revokes-emergency-use-authorization-chloroquine-and Accessed on November 21, 2020.

9. Clark C. AMA Policy Throws Shade on Diehard HCQ Docs - Delegates urge AMA to rescind policy discouraging the drug for COVID-19 patients; both sides say it's politics. 11/16/2020. Available at: https://www.medpagetoday. com/infectiousdisease/covid19/89705 Accessed on November 20, 2020.

10. Rodgers J. Drug Propped Up by Trump as Covid Cure Gets Mixed Billing in Senate Hearing. 11/19/2020. Available at: https://www.courthousenews.com/drugpropped-up-by-trump-as-covid-cure-gets-mixed-billingin-senate-hearing/ Accessed on November 20, 2020.

11. Sirotich E, Kennedy K, Surangiwala S, et al. Antimalarial drug shortages during the COVID-19 pandemic: results from the global rheumatology alliance patient experience survey. American College of Neurology Abstracts 2020. Available at: https://acrabstracts.org/abstract/ antimalarial-drug-shortages-during-the-covid-19-pandemic-results-from-the-global-rheumatology-alliance-patient-experience-survey/ Accessed on November 09, 2020.

12. Sterne JAC, Savović J, Page MJ, et al. RoB 2: a revised tool for assessing risk of bias in randomised trials. BMJ 2019; 366: 14898.

13. Higgins JPT, Savović J, Page MJ, Elbers RG, Sterne JAC. Chapter 8: Assessing risk of bias in a randomized trial. In: Cochrane Handbook for Systematic Reviews of Interventions version 6.1 (updated September 2020). Higgins JPT, Thomas J, Chandler J, Cumpston M, Li T, Page MJ, Welch VA (editors). Cochrane, 2020. Available from www.training.cochrane.org/handbook.

14. Moher D, Liberati A, Tetzlaff J, Altman DG; PRISMA Group. Preferred reporting items for systematic reviews and meta-analyses: the PRISMA statement. PLoS Med 2009; 6: e1000097. 
15. Hartung J, Knapp G. A refined method for the meta-analysis of controlled clinical trials with binary outcome. Stat Med 2001; 20: 3875-89.

16. Balshem $H$, Helfand $M$, Schünemann $H J$, et al. GRADE guidelines: 3. Rating the quality of evidence. J Clin Epidemiol 2011; 64: 401-6.

17. GRADEpro GDT: GRADEpro Guideline Development Tool [Software]. McMaster University, 2020 (developed by Evidence Prime, Inc.). Available at gradepro.org, Accessed October 02, 2021.

18. Mitjà $\mathrm{O}$, Corbacho-Monné $M$, Ubals $M$, et al. Hydroxychloroquine for early treatment of adults with mild Covid-19: a randomized-controlled trial. Clin Infect Dis 2020;ciaa1009. doi:10.1093/cid/ciaa1009.

19. Skipper CP, Pastick KA, Engen NW, et al. Hydroxychloroquine in nonhospitalized adults with early COVID-19: a randomized trial. Ann Intern Med 2020; 173: 623-31.

20. Johnston C, Brown ER, Stewart J, et al. Hydroxychloroquine with or without azithromycin for treatment of early SARS-CoV-2 infection among high-risk outpatient adults: a randomized clinical trial. EClinicalMedicine 2021; 33: 100773.

21. Reis G, Moreira Silva EADS, Medeiros Silva DC, et al. Effect of early treatment with hydroxychloroquine or lopinavir and ritonavir on risk of hospitalization among patients with COVID-19: the TOGETHER randomized clinical trial. JAMA Netw Open 2021; 4: e216468.

22. Schwartz I, Boesen ME, Cerchiaro G, et al. Assessing the efficacy and safety of hydroxychloroquine as outpatient treatment of COVID-19: a randomized controlled trial. CMAJ Open 2021; 9: E693-702.

23. Axfors C, Schmitt AM, Janiaud P, et al. Mortality outcomes with hydroxychloroquine and chloroquine in COVID-19 from an international collaborative meta-analysis of randomized trials [published correction appears in Nat Commun. 2021 May 14;12(1):3001]. Nat Commun 2021; 12: 2349.

24. Fiolet T, Guihur A, Rebeaud ME, Mulot M, Peiffer-Smadja N, Mahamat-Saleh Y. Effect of hydroxychloroquine with or without azithromycin on the mortality of coronavirus disease 2019 (COVID-19) patients: a systematic review and meta-analysis. Clin Microbiol Infect 2021; 27 19-27.

25. Kashour Z, Riaz M, Garbati MA, et al. Efficacy of chloroquine or hydroxychloroquine in COVID-19 patients: a systematic review and meta-analysis. J Antimicrob Chemother 2021; 76: 30-42.

26. Kashour Z, Kashour T, Gerberi D, Tleyjeh IM. Mortality, viral clearance, and other clinical outcomes of hydroxychloroquine in COVID-19 patients: a systematic review and meta-analysis of randomized controlled trials. Clin Transl Sci 2021; 14: 1101-12.

27. Kumar J, Jain S, Meena J, Yadav A. Efficacy and safety of hydroxychloroquine/chloroquine against SARS-CoV-2 infection: a systematic review and meta-analysis. J Infect Chemother 2021; 27: 882-9.

28. Chen P, Nirula A, Heller B, et al. SARS-CoV-2 neutralizing antibody LY-CoV555 in outpatients with Covid-19. N Engl J Med 2021; 384: 229-37.

29. May B. Regeneron's REGN-COV2 Cocktail Meets Clinical Endpoints in Phase II/III Trial. 10/30/2020. Available at: https://www.biospace.com/article/regeneron-s-regncov2-cocktail-meets-clinical-endpoints-in-phase-ii-iiitrial/. Accessed on October 02, 2021. 